\title{
The Site of Diversalizing: The Accomplishment of Inclusion in Intergenerational Dance
}

\author{
Maddy Janssens ${ }^{a}$ and Chris Steyaert ${ }^{b}$ \\ ${ }^{a}$ KU Leuven; ${ }^{b}$ University of St. Gallen
}

ABSTRACT In this study, we aim to revisit theorizing on inclusion by turning to practice theory. Challenging the individualist ontological assumption of most diversity and inclusion studies, we follow a practice-based theory of diversity to understand how an inclusive social order is accomplished. Our empirical case centres on the real-time practicing of a dance production where diversity was central to its production process as well as final performance. Using a research strategy of connected situationalism, we uncover and document three practices: mixing, inverting and affirming, that are recursively intertwined into a nexus, producing inclusion. We advance the inclusion literature by proposing the notion 'a site of diversalizing' that processually captures the accomplishment of multiplicity through practices and their associations in time and space, highlighting the necessity to understand 'practice' as the entanglement of bodily, discursive and material components, and approaching context as comprised of mutually constituting relations instead of micro/macro levels.

Keywords: connected situationalism, diversity, inclusion, multiplicity, nexus of practices, practice theory

\section{INTRODUGTION}

Please have a close look at Image 1, an image from Tornar, an award-winning intergenerational dance production, and try to sense its dramatic atmosphere: six people are running to escape a sandstorm. Heaps of sand fall from the 'ridge' of the theatre roof, blown by a powerful wind machine into a spiralling funnel, spinning like a tornado. We feel their agitation and anxiety as they are the only survivors, running for their life. The image also has a poetic force, as six, very diverse bodies are moving in unison, yet without a scripted notation of symmetrical movements. Rather, this diverse group is joint in destiny, flighting the disorder that comes with catastrophe

Address for reprints: Maddy Janssens, Faculty of Economics \& Business, Department of Work and Organization Studies, KU Leuven, Naamsestraat 69, 3000 Leuven, Belgium (maddy.janssens@kuleuven.be). 


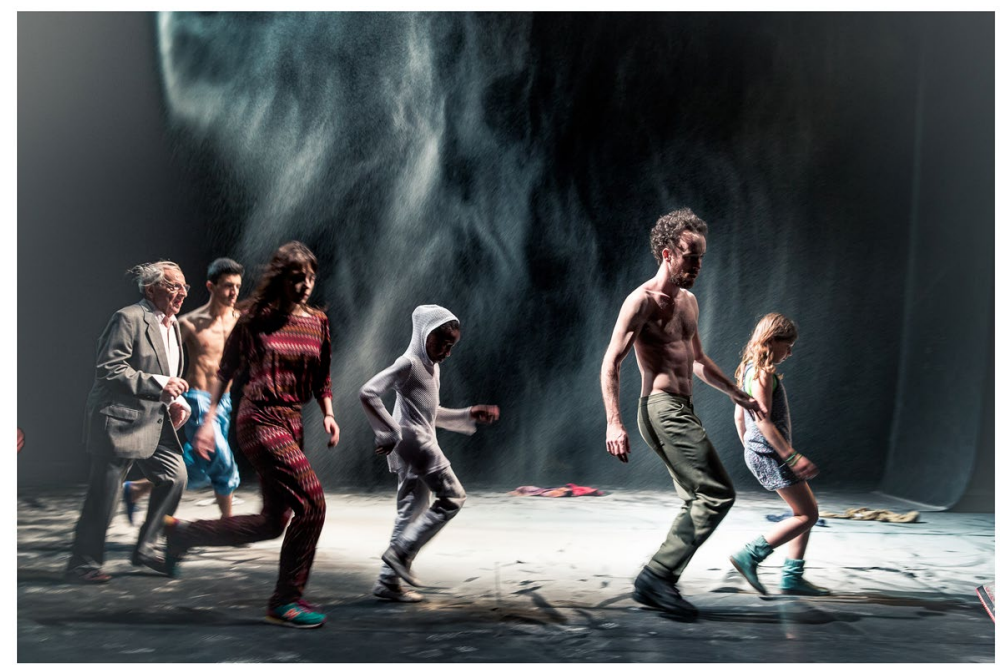

Image 1. The diverse community in the dance performance Tornar Source: (C) Danny Willems

and addressing such questions like: How to start anew? Who reaches out to whom? What kind of new language will emerge? How will this diverse group rebuild a promising new community?

In this paper, we argue that the creation and performance of this dance production - both what happens on stage as what happened behind stage - is strikingly relevant for diversity scholars who, now for almost three decades, have been studying how diversity practices can foster equality in a diverse organization (Cox and Blake, 1991; Ely and Thomas, 2001; Janssens and Zanoni, 2014; Kalev, Dobbin and Kelly, 2006). Yet, discrimination, exclusion and segregation continue to characterize most organizations (Nkomo et al., 2019) and our knowledge on the kind of practices needed to truly transform organizations into inclusive ones - where all members are 'fairly treated, valued for who they are, and included in core decision making' (Nishii, 2013, p. 1754) - still remains limited (Dwertmann and Böhm, 2016; Dwertmann, Nishii and van Knippenberg, 2016).

Throughout the diversity literature, responses to ending workplace exclusion and marginalization have evolved - from compliance to legislation, affirmative action, diversity management to recently the inclusion approach (Nishii, 2013; Nkomo, 2014). Yet, despite this evolution in searching for ways to reduce discrimination and leverage the advantages of diversity, the underlying ontological assumption has remained the same. In particular, diversity research tends to be characterized by an individualist assumption holding that social life in a diverse organization can be best understood through studying properties of persons and interpersonal relations (Schatzki, 2005). For example, discrimination is explained by individuals' cognitive biases (Milliken and Martins, 1996), diversity-related conflict through in/outgroup dynamics (van Knippenberg and Schippers, 2007), and inclusion by fulfilment of personal needs for belonging and uniqueness (Shore et al., 2011). In line, practices that would enhance diversity and inclusion tend to be oriented at individuals, such as reducing stereotypes, mentoring programs for women and ethnic 
minorities, and allowing people to express core aspects of their self-identities (Nishii and Rich, 2014; Roberson, 2013).

Yet, this ontological stance of individualism tends to neglect that social life of a diverse organization is more complex than only consisting of individuals. Rather, a full account of social life requires a turn to 'extra-personal' phenomena such as modes of production, social systems, structure and discourse (Schatzki, 2005). To capture this complexity, we turn to practice theory and its alternative post-dualistic ontology in which the relation between personal and extra-personal features is theorized as recursive, not dialectical. Human action and social order are then no longer explained in terms of unhelpful, traditional dichotomies such as agency/structure, mind/body and social/material (Feldman and Orlikowski, 2011; Sandberg and Tsoukas, 2016), but through their participation in a nexus of practices (Nicolini, 2011). Taking this ontological stance, we hope to contribute to the development of new theoretical premises that help to better understand the accomplishment of inclusion.

The purpose of this paper is thus to revisit theorizing on inclusion by turning to the logic of practice theory. We follow the principles of a domain-specific application of practice theory to diversity (Janssens and Steyaert, 2019) and interpret the real-time practicing of an affirmative case to uncover the situated practices of how a social order of inclusion is accomplished. Key to a practice-based theory of diversity is that no longer individuals but 'practices' are the unit of analysis. Practice theory (Nicolini, 2013; Sandberg and Tsoukas, 2011; Schatzki, 2001) gives ontological primacy to practice, arguing that 'social reality is fundamentally made up of practices; that is, rather than seeing the social world as external to human agents or as socially constructed by them, this approach sees the social world as brought into being through everyday activity' (Feldman and Orlikowski, 2011, p. 1241). Importantly, the notion of practice is not taken in a common-sense way (as mostly done in diversity literature) but follows a theoretical logic. In particular, a practice needs to be understood as an entanglement of body, materiality and discourse, and is connected with other practices in time and space, hereby producing a particular kind of social order.

Empirically, we turn to an affirmative case, in line with recent calls for more positive and enlightening empirical research (Janssens and Steyaert, 2019; Shore, Cleveland and Sanchez, 2018). The case is a dance production, a 'perspicuous setting' or a real world setting where the topic in question [diversity] is a prominent feature of a day's work (Garfinkel and Wieder, 1992) as well as part of a longer organizational trajectory. Experimenting with differences is in 'the DNA' of the more than thirty-year old, entrepreneurial dance organization, Ultima $\mathrm{Vez}$ - considered one of the pioneering players in (re)shaping contemporary dance. Following this case over the course of more than two years, as well as retrospectively looking back at the production of the intergenerational dance performance, Tornar, our research question is: How is the inclusive social order at this dance production created? Through which bundle of practices and with what effects?

Studying this 'extreme' case from a practice perspective, we uncovered three intertwined practices that accomplish an inclusive social order. The practice of mixing involved an active combining of individuals with a different background through which habitual positions were suspended and affective bonds could be developed with unfamiliar 
others. The practice of inverting further enabled multiplicity through highlighting the distinctiveness of differences and reversing uneven positions, granting equal value to any kind of difference. The practice of affirming additional reinforced the accomplishment of inclusion as, through constantly repeating and experimenting with the newly developed understanding of diversity and dance, collective embodied dispositions emerged. From this, we develop three theoretical premises that advance the inclusion and diversity literature, proposing 1) the novel notion of 'site of diversalizing' or a nexus of practices and their associations in time and space that recursively produce multiplicity in a processual way, 2) a theoretical understanding of 'practice' as the entanglement of body, materiality and discourse, and 3) an re-conceptualization of context as comprised of mutually constituting relations.

\section{INGLUSION: AN INDIVIDUALIST STANGE ON VALUING DIVERSITY}

After three decades of diversity studies, scholars increasingly focus on inclusion to promote the potential advantages and opportunities of having a diverse workforce (Ferdman and Deane, 2014; Mor Barak, 2005; Nishii, 2013; Roberson, 2006). They aim to move beyond diversity management that has focused primarily on increasing the representation of members of disadvantaged groups and instead, attend to the value that people with a variety of differences bring to the organization (Ferdman, 2014). While the interest in inclusion is increasing, scholarship focused on inclusion is still in the initial stages, with many ideas and approaches to define inclusion - inclusion, work group inclusion, leader inclusion, perceived organizational inclusion, inclusion climate, inclusion practices, - but little consensus of how to proceed and a call for more enlightening empirical research (Shore et al., 2018).

The main argument of our study is that scholarship on inclusion will advance through taking a different ontological assumption. Reviewing the inclusion literature, we notice that scholars bring in several novel inclusion-related concepts but hold on to the same individualist ontological stance as before. In particular, the unit of analysis to capture inclusion refers to individual beliefs, experiences or perceptions, assuming that inclusion can be best captured by individual properties. For example, inclusion is understood as 'people's belief that they can be safe, heard, engaged, fully present, authentic, valued, and respected, both as individuals and as members of multiple identity groups' (Ferdman, 2017, p. 239), or as the fulfilment of personal needs - 'an employee perceives that he or she is an esteemed member of the work group through experiencing treatment that satisfies his or her needs for belongingness and uniqueness' (Shore et al., 2011, p. 1265). Further, when investigating ways to create inclusion, studies tend to emphasize the quality of leadership or what leaders can do to promote workplace inclusion (Brimhall et al., 2017; Nishii and Mayer, 2009; Randel et al., 2018), hereby again assuming that it are properties of individuals and individual relations that can foster inclusion.

So, the question arises to what extent we can really advance our knowledge on diversity and inclusion within organizations if the ontological assumptions underlying a theory are not investigated, questioned and/or changed (Alvesson and Sandberg, 2011; Sandberg and Tsoukas, 2016). Similar as pointed out by Nkomo (2014, p. 580), the danger exists that the concept of inclusion is merely 'a case of old wine in new bottles' as 
'one might ask whether, indeed, this was not also the aim of diversity management in organizations'. In this study, we highlight two main problems of an individualist ontological stance e.g., its tendency to prioritize cognition over other central components of human action, and the understanding of context through the micro/macro divide. Both hinder in our view a full understanding of the complexity of inclusion.

First, with an individualist stance comes often the focus on cognition or the idea that the social is primarily located in the human mind (Reckwitz, 2002; Sandberg and Dall'Alba, 2009). Mental structures and activities are treated as the ontological realm of the 'inner' that cause or are conditions of the 'outward' human behaviour. Yet, by prioritizing mental qualities, this stance neglects the importance of other components like forms of bodily activities, states of emotion and material things and their use (Reckwitz, 2002). Such 'mentalism' is very much the basis of diversity and inclusion studies that are grounded in psychological theories. For instance, relying on social identity theory, inclusive leadership is seen as related to individual difference characteristics such as pro-diversity beliefs, mental openness or levels of cognitive complexity (Randel et al., 2018), thus assuming that mental activities drive the propensity of inclusive leader behaviours. Similar, drawing on social information processing theory, authentic leadership is considered crucial in fostering workplace inclusion as their 'inherent' ethical behaviour drives their decision-making processes (Boekhorst, 2015).

Critical diversity scholars have already argued the need to go beyond cognitive processes to fully understand the persistent role of gender, ethnicity, (dis)ability and age in structuring workplaces unequally. In particular, they have turned to discourse or structured collections of texts that bring concepts, objects and subject positions into being (Hardy and Phillips, 2004) to examine how diversity, identity and power relations are exercised in discursive activity. For instance, the discourse of 'business case' has been criticized for its controlling nature, constructing socio-demographic identities as economic resources which further reproduces the subordinate positions of members of disadvantaged groups (Lorbiecki and Jack, 2000; Noon, 2007; Zanoni and Janssens, 2004). While this body of critical discursive studies has well shown how text and talk are key resources in shaping meaning, it has only paid limited attention to the relation of these meanings with other non-discursive social practices - a concern which is increasingly acknowledged (Zanoni and Janssens, 2015). Our argument in this paper is the need to fully acknowledge non-discursive practices like bodily practices and material use (Reckwitz, 2002) in order to fully understand how diversity and power relations are enacted, reproduced and resisted.

Second, an individualist ontology tends to hold on to individuals as unit of analysis, even when recognizing the importance of context. The concern to not disregard 'context', and thus following to a certain extent the plea of critical scholars to attend to broader organizational structures and routines that reproduce power inequalities in a structural way (Acker, 2006; Zanoni et al., 2010), is increasingly taken up by inclusion scholars. In her work on 'inclusion climate', Nishii (2013) is one of the first to emphasize the need to recognize the importance of organizational environments, highlighting three dimensions that constitute climate for inclusion - fairly implemented employment practices, integration of differences, and inclusion in decision making. This notion of inclusion climate is increasingly adopted, mostly as a moderator to further explain 
diversity-related outcomes (Dwertmann and Böhm, 2016; Nishii, 2013) but the argument is also made to understand inclusion itself at the organizational or group/unit level. For instance, Ferdman (2017, p. 239) suggests to see inclusion as a multilevel system and set of practices: 'Inclusion spans and connects macro, meso, and micro processes and contexts, ranging from societal and organizational ideologies, values, policies, and practices, to leadership models and practices and group norms and climates, to interpersonal behavior and individual experiences of inclusion'. Yet, despite this attempt to capture the socio-relational context within which heterogeneous individuals interact (Nishii, 2013), the individualist assumption remains. It is recognizable in the call for multi-level research (Dwertmann et al., 2016) where, despite all research strategies to study inclusion at multiple levels, individuals remain the central unit of analysis. Scholars conceive social reality along a micro-macro divide, hereby overlooking how context may be co-constitutive with individual actions and experiences (Steyaert, 2016). This latter conception is also not held by critical scholars who tend to highlight structural aspects of social reality (like discourse, production systems) as if they are independent of human action.

In sum, the inclusion literature has introduced a range of concepts that, despite the claim of novelty, remain grounded in an ontology of individualism. This latter comes with the problems of a continuing focus on the cognitive component of human behaviour and the assumption that inclusion can be fully understood by attending to individuals and interpersonal relations, even when organizational 'level' notions like inclusion climate are used. It is our argument that inclusion research might benefit from questioning this individualist ontology and instead turn to a different ontological assumption: the relational ontology of practice theory. In the next section, we introduce this theoretical lens, indicating its main premises and its implications for ways to study and understand inclusion and its production.

\section{A PRACTICE-BASED THEORY OF DIVERSITY: STUDYING INGLUSION THROUGH A BUNDLE OF PRAGTIGES}

Taking a practice lens to understand diversity and inclusion in organizations fundamentally re-shapes theorizing on inclusion. Following the premises of a practice-based theory of diversity as outlined by Janssens and Steyaert (2019), we forward here the ontological primacy of practice and its consequential re-conceptualization of inclusion, the theoretical logic of inclusive practices, and a research strategy of connected situationalism, both uncovering situated and connected practices to accomplish inclusion.

\section{Inclusion as a Social Order Enacted through a Bundle of Practices}

Central to practice theory - 'not a full-blown grand theory' (Reckwitz, 2002, p. 257) but a rather broad family of theoretical approaches (Nicolini, 2013; Sandberg and Tsoukas, 2016) - is the orientation towards 'practicing, real-time doing and saying something in a specific place and time' (Nicolini, 2013, p. 219), and the ontological stance that these situated actions are consequential in the production of social life (Feldman and Orlikowski, 2011). Practice theory 'locates the social in "practices" (Sandberg and Dall'Alba, 2009, p. 1352), not in the human mind or behaviours as currently done in inclusion research. 
As practice has ontological primacy, the fundamental implication is a shift from individuals to practices as unit of analysis. Practice theory forces us to move away from methodological individualism, or 'the reductionist tendency to explain behaviour wholly in terms of the actions of discrete individuals or groups of individuals' (Vaara and Whittington, 2012, p. 288). It implies that the focus of investigating social and organizational phenomena is not on individuals, their roles and actions but on practices and their associations in time and space (Nicolini, 2013). Or as stated by Nicolini (2013, p. 178): 'the object of inquiry should be managerial and entrepreneurial activities, not managers and entrepreneurs; strategy making and sales practices, not strategists and salespersons; leadership practices, not leaders'.

This ontological stance implies a fundamental re-conceptualization of inclusion. Following the idea that a social reality is made up of practices, inclusion needs to 'be seen as the result of net-effects produced and reproduced through practices and their associations' (Janssens and Steyaert, 2019, p. 32). Inclusion becomes a particular social order of a diverse organization, being the result of meaning making, identity-forming and order-producing practices (Chia and Holt, 2008; Nicolini, 2013). Diversity and inclusion scholars thus should no longer focus on individuals, whether it be minority employees, majority employees, diversity management practitioners or leaders but on those practices that contribute to the creation and perpetuation of an inclusive social order of a diverse organization. This re-conceptualization does not imply that the meaning of inclusion changes - it still refers to feelings of being accepted, valued and recognized; rather it forwards a rationale of a different ontological-epistemological stance (Sandberg and Tsoukas, 2011), seeing inclusion as seemingly stable features of a social organizational order, transpiring amidst and through practices and their associations.

Seeing apparently durable features of organizations (like horizontal and vertical segregation) as the result of some type of productive and reproductive work (Martin, 2003; Nicolini, 2013) implies that practice theory also engages with questions of power. We forward here the central argument that practice is a mode of ordering such that 'power relations are always and only the effect of the performance of practices [...], [they] never result only from distinct, specifiable, moments of practice but are effects of the ordering and the churn of innumerable moments of practices' (Watson, 2017, p. 181). Studying inclusion through practice theory thus inherently informs us about power relations or as Barnes (2001, p. 28) indicated: 'talk of practices is talk of powers'. It underscores the questioning of the 'natural' order of things through uncovering how practices and their connections produce and reproduce a certain social order like the emergence and stabilization of an inclusive social order or, in contrast, the very resilient discriminatory unequal social order of many diverse organizations.

\section{Theoretical Logic of Inclusive Practices}

Understanding a social order of inclusion through practices further asks for adopting the theoretical logic of practice. Until now, inclusion scholarship (just as in diversity management) has approached the notion of practice mostly in an a-theoretical, common-sense way (Sandberg and Tsoukas, 2016). The notion of inclusive practices is used to refer to fair employment practices, inclusive HR practices, practices that value and integrate diverse 
perspectives, create opportunities for employees to share whole selves, and increase inclusion in decision making (Dwertmann et al., 2016; Nishii and Rich, 2014), yet without considering that practice itself is a theoretical notion. What is missing is an investigation into inclusion practices 'as practice', in a more informed way, and thus, to 'provide more accurate accounts of the logic of practice' (Sandberg and Tsoukas, 2016, p. 188).

Capturing the theoretical logic of practice requires the study of how a practice is accomplished through the connection between bodies, tools and artefacts, and discursive resources. While different definitions of a practice exist, a practice is conceived as simultaneously discursive, embodied and material (Nicolini, 2017a; Sandberg and Tsoukas, 2016). Discursive practices or language in action are central to the accomplishment of a practice, yet practice theory emphasizes that a practice cannot be reduced to only words and foregrounds as well the role of the body and artefacts in all human affairs (Nicolini, 2013). Practices are embodied, inscribed in the body through learning and repeated injunctions, being partially routinized, partially improvised (Nicolini and Monteiro, 2017; Reckwitz, 2002). And they are inherently material in nature as, within a practice, tools, objects and artefacts contribute to how the practice is carried out and made possible (Orlikowski, 2000) and shape meaning (Gherardi, 2016).

Adopting this theoretical logic, we thus endorse the idea that inclusive practices consists of a set of real-time doings and sayings, mediated by the way in which discourse, materiality and our bodies are entangled (Nicolini, 2017a). Looking at the embodied, material and discursive entanglement and its accomplishment is required to understand how a practice becomes a social order-producing practice that is inclusive in nature.

\section{Research Strategy of Connected Situationalism}

Key to connected situationalism is that the basic unit of analysis is not a single scene of action or instance of the accomplishment of a practice, but rather 'a chain, sequence or combination of performances plus their relationships - what keeps them connected in space and time' (Nicolini, 2017b, p. 101). In other words, it entails starting from a 'here and now' and following connections (Nicolini, 2009a).

The 'here and now' is crucial as it adheres to the main premise in practice theory that the social is always accomplished in situ. So, a first step is zooming-in on a range of activities, the doings and sayings in a specific place and time, and approaching them as knowledgeable accomplishments (Nicolini, 2009a, 2013). Although logically predominant, this orientation entails a major challenge for empirical research. As Nicolini (2017a) indicates, while practices can be conceived individually, empirically, a variety of practices always intersect within a particular scene of action and are knotted together. So, for an empirical researcher, the question is: Which practices am I observing? What practices are circulating in and through the scene of action and which ones are relevant for understanding the inclusive social order? As practice is a second-order abstraction, a main challenge thus is to find out a relevant practice before we can study it (Nicolini, 2017a; Nicolini and Monteiro, 2017).

To further assist the uncovering of inclusive practices, we 'zoom out' (Nicolini, 2009a) to other scenes of actions. By zooming out in space, we acknowledge the central idea of 'connectedness in action' (Gherardi, 2006), following the premise that a local 
accomplishment never happens in isolation and cannot be carried out independently of other scenes of actions and practices. By tracing these connections and its endless series of relationships which continually move into each other (Gherardi, 2017), it will become visible how inclusion can emerge from intertwined practices. We thus attend to the association between practices in time and space as well as to the reciprocal implications, proposing in the discussion the notion of 'site' (Nicolini, 2011; Schatzki, 2005) to indicate how a bundle of practices recursively accomplishes an inclusive social order.

\section{GASE STUDY: AN INTERGENERATIONAL DANGE PERFORMANGE Choice of Case: Diversity in a Greative Organization}

The empirical analysis presented in the next section is based on 2 and a half year investigation of an intergenerational dance performance, called 'Tornar', produced by the choreographer Seppe Baeyens in the context of the internationally renowned dance company 'Ultima Vez' (UV), located in Molenbeek, an impoverished suburb of Brussels. Access to this case came about after a practitioner-talk on diversity by the first author where a member in the audience hinted at her brother's artistic work in dance, experimenting with differences in an unseen way. Looking at that time for ethnographic access to an affirmative case, and having anecdotal evidence that UV had incorporated diversity of all kinds in its performances - different age groups, transcultural set ups, blind dancers, and different images of sexuality, we explored the possibility of research.

The dance performance Tornar tells the story of a diverse group of people left after the passage of a tornado who are trying to rebuild a community. The movement of the devastating tornado is a metaphor for the crumbling solidarity between generations. The point of departure is age but we also attend to the 'intersectional' relations with gender (embodiment of dance), ethnicity (a multicultural cast), professionality (professional as well as non-professional dancers) and linguistic background (mainly Flemish, French and English but also other languages). This mix of diversity dimensions is well aligned with the current agenda in the (performative) arts and cultural industries to make performances on and behind the stage more diverse (Finkel et al., 2017). However, we do not consider these diversity dimensions as static features of individuals, but aim through our praxeological study to reconstruct the process of how diversity and inclusion is accomplished both during the production process as well as during the performance.

\section{Data Collection}

The empirical program of a practice lens is 'ethnographic in its sensibility' (Miettinen, Samra-Fredericks and Yanow, 2009, p. 1312) because it wants to study practice as something that is done in everyday life (Nicolini, 2017a). However, accounting for everyday practices is not done in an isolated way, which implies that we not only followed rehearsals and performances but also extended data collection to other scenes of (inter)action to understand how practices can happen in the first place.

The data collection was done in 12 periodical stages, clustered around artistic events (rehearsals, festivals, auditions, book launch and film) and open dance workshops. Each period, 
we engaged in ethnographic observation and interviews, and gathered data from archival sources. Our ethnographic observation was focused on attending rehearsals, try-outs, performance days and dance workshops to observe the 'doings and sayings' of the dance group while interacting, rehearsing and performing. As researchers, we were embedded in the day programs, thus also participating in lunches, breaks and briefings. In total, we observed 2 repetitions of Tornar before a public performance, and 23 open dance workshops (ranging from 2 hours to a full day) held at schools in Molenbeek, the studio of UV or performance locations. We started observations when Tornar had already had its opening night. Yet, we reconstructed the preparation and rehearsal period of Tornar based on observations of its touring activities until 'its dernière' fifteen months later and open dance workshops (where most cast members of Tornar were also present) during holidays or in preparation of the next production. During the observations, we kept a virtual 'logbook', a series of ethnographic notes (Ybema, Yanow, Wels and Kamsteeg, 2009) that both authors wrote down and completed at the end of each observation episode. We initially also took pictures during rehearsals but realized that we could draw upon UV's extensive, professional photo-taking and video-taping of rehearsals.

The interviews were conducted to complement our observations. We conducted interviews with the choreographer $(\mathrm{N}=6)$, staff members of $\mathrm{UV}(\mathrm{N}=17)$ and Tornar dancers $(\mathbf{N}=2)$ as well one group interview with all Tornar dancers. Interviews in the different episodes had a different focus. Initial interviews had an open format and were mainly aimed at investigating the emergence of Tornar. The first interview with the choreographer covered his artistic trajectory and view on intergenerational dance; the initial interviews with the staff members of UV focused on UV's history and vision on dance and the start of community work in Molenbeek; the interviews with the dancers covered their contact with UV and their experience of being engaged in intergenerational dance. Later interviews were aimed at better understanding the activities that we observed in the different artistic events and dance workshops. We asked the interviewees about how they understood and experienced the activities, also asking for specific examples and detailed stories regarding the events they described. Further, in line with the principle of an interview to the double (Nicolini, 2009b), we asked the choreographer and the dancers (in informal discussions) very concrete, detailed description of the activities in between our observation periods, sometimes complemented with video-material of rehearsals we did not attend. Interviews lasted from one hour to 3 hours, and were recorded and transcribed.

Finally, over time, we collected documents that would help us better understand the production process and performance of Tornar as well as the broader field of dance. We conducted searches of Tornar's press reviews, the website of UV, and reports on the evolution of contemporary dance landscape over the last 30 years, both in Flanders, Belgium and internationally. Moreover, our interviewees shared with us internal documents like the subsidy applications to the government of Tornar (the development as well as production application), flyers and press releases of Tornar, and the 4-year term subsidy application of UV. We also read articles, book chapters and master theses on UV and contemporary dance, and watched videos produced by UV. These documents, which form a core element of the public framing of the dance company's activities, gave us further access to the discursive and material enactment of the bundle of practices. 


\section{Data Analysis}

Our analysis followed interpretative research (Yanow and Schwartz-Shea, 2006) with cycles of data collection and interim analysis to orient the next part of the data collection through our field notes of the observations, multiple readings of the interview transcripts, and the documents. The data analysis was informed by our interest to develop a processual (and non-reified) understanding of inclusion-producing practices which we, in line with the theoretical logic of practice, conceived as an entanglement of bodily enactments, and spatio-material and discursive mediations. Importantly, while activities in this case were often initiated by the choreographer, our analysis focused on the practices that these activities are part of. Further, following a posthuman approach of practice theory (Latour, 2005; Nicolini, 2011), we paid attention to how material things are necessary and active elements of practice.

Stage 1: Identifying the components of a practice. To capture the three components of practice, we were guided by sensitizing questions (see Nicolini, 2013, p. 220) which we used to iteratively analyse and interpret our observation and textual material in terms of practice-related accomplishments and mediations. In particular, attending to how a practice is accomplished through the body, we analysed the various bodily interactions and affective resonances that come with them. Taking the question of material mediation, we identified the importance of specific social technologies (professional dance patterns, improvisation techniques, etc.) as well as material and spatial artefacts. Finally, attending to the discursive enactment of a practice, we distinguished between practical concerns and aesthetic frames. Table I presents the three analytical questions and our related interpretative distinctions.

Table I. Analytical framework of practice

\begin{tabular}{|c|c|c|}
\hline $\begin{array}{l}\text { Composition of a } \\
\text { practice }\end{array}$ & Analytical question & Interpretive distinction \\
\hline $\begin{array}{l}\text { Embodied } \\
\text { component }\end{array}$ & $\begin{array}{l}\text { How is the practice accomplished } \\
\text { through the body? }\end{array}$ & $\begin{array}{l}\text { Bodily interactions - running in circles as } \\
\text { group, holding someone on your feet, eye } \\
\text { contact while walking } \\
\text { Affective resonances - openness, feeling } \\
\text { comfortable to experiment }\end{array}$ \\
\hline $\begin{array}{l}\text { Material } \\
\text { component }\end{array}$ & $\begin{array}{l}\text { How is the practice mediated } \\
\text { through tools, artefacts and } \\
\text { spaces? }\end{array}$ & $\begin{array}{l}\text { Social technologies - use of improvisa- } \\
\text { tion techniques, feedback through } \\
\text { video-reviews } \\
\text { Material artefacts - dance studio, chairs, } \\
\text { subsidy applications, invitation leaflets }\end{array}$ \\
\hline $\begin{array}{l}\text { Discursive } \\
\text { component }\end{array}$ & $\begin{array}{l}\text { How is the practice articulated } \\
\text { discursively (verbally, textually, } \\
\text { visually)? }\end{array}$ & $\begin{array}{l}\text { Practical concerns - dance as image of soci- } \\
\text { ety's diversity, learning from each other } \\
\text { Artistic frames - focus on authentic connec- } \\
\text { tions, asymmetrical contrast }\end{array}$ \\
\hline
\end{tabular}


Stage 2: Identifying the bundle of practices. Further interpreting the range of activities in light of the overall research question of how an inclusive social order is accomplished through a bundle of practices, we looked for how a range of activities clusters into one or more practices and how these activities are connected with various interrelated activities. We iteratively searched for similar kind of doings and sayings in related scenes of action to identify which practices are circulating and which ones are relevant (Nicolini, 2017a). Through several meetings in which both authors discussed the importance and relevance of activities for inclusion, we came to the interpretation that three practices - mixing, inverting, and affirming - form together a practice-net, a 'regime of performances' (Nicolini, 2017a). These three practices and their associations in time and space all contribute to the accomplishment of multiplicity, which we forward as inclusion-producing. To ensure the trustworthiness of our interpretation, we discussed it with the choreographer, a few dancers and staff members whom we regularly sent draft versions of our reports. This social validation revealed that our bundle of practices was a trustworthy, recognizable depiction of the inclusion producing practices that occurred during the creation and performance of this dance production.

Stage 3: Theorizing on inclusion-producing practices. In an attempt to turn our analysis into theory building, we further became alert to the risk of reifying the nature of the practices, as emphasized by Nicolini (2017a). We formulated a first theoretical insight on understanding inclusion through its processualism, calling this a process of 'diversalizing', a processual reading of Mignolo's (2000) concept of 'diversality' to give meaning to our integrative interpretation that differences are a core 'universal norm' to realize inclusion. In addition, attending to the association of practices in time and space, we emphasized the intertwined nature of the practices, calling this a 'site' or a nexus where the practices of mixing, inverting and affirming and their spatio-temporal intersections mutually strengthen each other. Combing both theoretical insights and inspired by Nicolini's (2011) notion of the site of knowing, we concocted the term 'site of diversalizing' that we will now uncover in the results section.

\section{UNGOVERING THE SITE OF DIVERSALIZING}

In this section, we show how a 'site of diversalizing' is accomplished through the interrelated, inclusion-producing practices of 'mixing', 'inverting' and 'affirming'. For each practice, we document its embodied, material and discursive accomplishment within the artistic group setting, and then its connection with similar activities in other scenes of actions. Together, all three practices and their intertwined nature contributed to a social order where multiplicity was enabled, highlighted and strengthened, leading us to argue for the emergence and stabilization of a 'site of diversalizing' where the core norm is multiplicity.

\section{The Practice of Mixing}

Mixing to suspend individuals' habitual positions. The cast of Tornar consisted of a group of four children, two adolescents, three adults, a 91-year old man and a musician. This 
exceptional diversity, not only in terms of age but also gender, professional background, linguistic and ethnic variety, strongly contrasts with the usual look of professional dancers as young, healthy-looking and fully-abled. While one might argue that age diversity is a condition to make an intergenerational dance performance, the presence of diversity was much more than this. Rather, the practice of mixing involved an active combining of individuals with a different background through which routine and habitual norms and roles are left behind.

We observed this dynamic of mixing in the dance workshops. Participants could never stay long with somebody of their age group, but were asked to make pairs or small groups with an older/younger person(s). They then engaged in a series of exercises to explore their different bodily proportions and possibilities of moving together. For instance, children stood on the feet of seniors who then crossed the room with them. Or, a small group of a child, adolescent, adult and elderly person explored different bodily possibilities like how a small and a tall body may lean on each other while keeping balance. Through such continuous interactions, different generations were getting used to and comfortable with moving with each other. One elderly woman told us during the break of an open dance workshop:

In the beginning, you had to get used to it [the dance workshop]. But having the children present, that makes it special for us. You develop a bond with them, and yeah, what if we [only elderly persons] would only be by ourselves, we know we are no dancers (Cecile, observation).

Our observation further suggests that this practice of mixing was mediated by the social technology of joint circle time and improvisation techniques. The sessions always started with joint circle time where everybody sits on the floor next to each other, reflecting on last time's session. The pedagogical tool of the circle made everybody visible, with an equal distance to the centre, producing diversity without hierarchy. Improvisation techniques were further used to mediate the accomplishment of mixing and expand the range of dance interactions and playful responses participants could draw upon.

The maximal diversity based on mixing was also discursively accomplished through the choreographer's practical concern and artistic frame. The need for diversity in dance was explicitly argued for, a discursive resource that many press articles on Tornar emphasized:

'I find it always strange when a choreographer claims to bring an image of society on stage while he is only working with schooled dancers in their twenties? This does not make sense really' (press article).

This practical concern orients the practice of working with individuals that do not adhere to the typical image of a professional dancer. Even more, the story of the performance can only be told by bringing on scene a diverse group of people: children, adolescents, adults and elderly, a small community that reflects society. Also the artistic frame contributed to the accomplishment of this practice. The vision on dance is here one of dance being a language that genuinely connects. Rather than technique, a balanced group 
choreography or symmetrical movements, artistic quality implies honest, authentic connections in the moment of the dance performance itself:

'Working with several generations, what stands out for me is not so much the technique but honesty. I want to show them as they are, that is something personal but I don't like it when somebody acts, not on stage and not in real life. I'm searching for something authentic at the scene, no hiding behind the technique' (interview with choreographer).

Inquiring into the effect of this practice, our material suggests that the mixing produced the suspending of individuals' habitual relational positions. It accomplished a kind of 'unfreezing' from the norms associated with a particular socio-demographic group, so that different kinds of relations among individuals could be explored. This was especially experienced by the teenagers playing in Tornar. Rather than being confronted with subgroup norms and having to behave 'cool', they experienced no scruples to try out new, unusual movements. Ischa, for instance, who used to impress with breakdancing, felt comfortable to move differently:

'when we came together to develop Tornar, we did not know each other at all. I think that was our main trump card because we had no boundaries towards each other; you can be yourself as nobody knows what to expect from you; you don't have to feel ashamed as you fear to lose your position in the group; you can totally let go when you don't know each other' (group interview with dancers).

Mixing thus was an important practice where the presence of 'many others', unknown to each other, liberates individuals from expectations conform their age group, gender or ethnicity, and as encultured by family, education and religion. It accomplished the emergence of interactions where existing power asymmetries as reflected in norms, identity fixations or privileges were suspended. Rather, new interactions could be explored through which the participants gained an affective bond with each other, starting to appreciate the unusual movements and new relations.

Mixing in other scenes of action. Zooming out to related scenes of action, the practice of mixing was strongly associated with the efforts of UV to become an Open House in Molenbeek, which enabled the active search for diverse participants. Located in this impoverished multicultural Brussels' suburb, the dance organization had set up a community project through which they wanted to invite new social groups to the field of dance. In particular, they organized open dance workshops during the school holidays so that all kinds of people from the neighbourhood and beyond could become acquainted with dance. Image 2 gives an impression of the diversity in these workshops.

Most performers of Tornar had once joined these dance workshops, as was also the case for Leon, the 91-year old man. The story how he, a retired butcher, was invited to join and became a dancer became a classic one, featuring in all press articles reporting on Tornar. Leon also told us: 


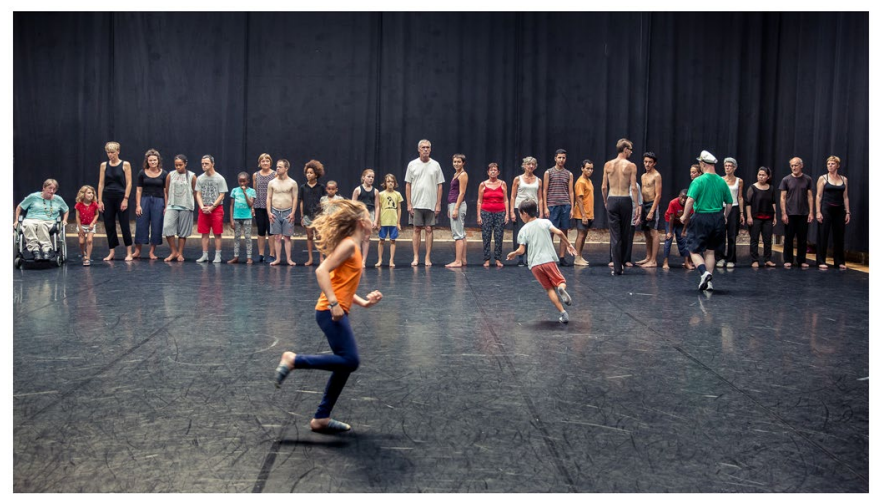

Image 2. The range of diversity in an open dance workshop Source: (C) Danny Willems

'I was walking in the street, I live just across Ultima Vez. And Seppe was standing in the door, smoking a cigarette. He asked me whether I was interested in joining the workshop that they organized the next week. He told me that he was working with people from different ages. And I went the first day, just for one hour; then the second day I stayed a bit longer, and the third day, I wore my sweatpants and told Seppe: I'm in'.

The rather casual way in which Leon entered the cast should not give the impression that the invitation of 'unusual suspects' is just a lucky-shot. Rather, inviting a diverse group was based on close collaboration with various local organizations - schools, youth centres, meeting places for elderly, refugee centres. As indicated by Sam, responsible for the community work at UV, their participation often required additional socio-material arrangements such as transport for physically disabled participants or a buddy system that focused on taking care of participants who for instance were blind or had down syndrome during meals or restroom breaks. These activities thus enabled the mixing, leading to the diverse cast of Tornar.

Inquiring into the effects of these connections, we forward the idea that the practice of mixing and its connection to the inviting activities of the organization started to produce a site, a nexus of activities that support and enable each other. The mutual implication between the practice and the site in which it is located, helped the emergence of multiplicity where typical norms associated with socio-demographic groups are suspended, hereby bracketing power asymmetries, while affective bonds among different individuals are nurtured. A challenge though is that the unusual suspects invited to join dance might be so well integrated that they actually become the 'usual suspects'. Therefore, the practice of mixing requires a constantly renewed invitation. Over the years we observed how the original focus on intergenerational mixing expanded to inviting people from increasingly wider circles, including different ethnic backgrounds (North Africa, EastEuropean and Middle Eastern backgrounds), mentally and physically disabled persons, and refugees. This makes it increasingly unlikely that dance is predestined for the young, beautiful, well-trained and muscular. 


\section{The Practice of Inverting}

Inverting to highlight multiple, contrasting positions. The inclusive social order was further accomplished by the practice of 'inverting'. This practice involved reversing stereotypical roles and assumptions as well as enlarging and valuing the differences through which multiple, contrasting positions were accomplished. The following observation of an exercise in a dance workshop illustrates this practice well:

The children are given the role of choreographer meaning that they need to improvise, choose movements and jumps which then the elderly have to copy and mirror. The children do so...

But two minutes within the exercise, Seppe shouts to the children: 'Choreographers, do your job! Try to make the movements larger, more quality, bigger jumps. You can make movements that Pierre (an elderly man) cannot make. Do so, make sure you make jumps they cannot do'.

The children giggle, look at each other but then start to jump as high and far as they can...

Yet, a few minutes later, Seppe again intervenes: 'Kids, you make it too easy for them. It is much more exciting when they are NOT able to copy. You cannot adjust yourself. I like to see their limitations'.

In this exercise, and very common throughout the workshops, roles are reversed - children, not the elderly are the choreographers - so that current assumptions about generations are questioned. In line, a journalist who sat in on a rehearsal for Tornar wrote afterwards in her article: 'the cliché is that children learn from the elderly and that children imitate adults, but here I just as well witness the reverse' (newspaper article). Next to roles, assumptions about differences are inverted. Instead of adjusting to each other or minimizing the difference, activities are all focused on making the difference larger and more visible. The choreographer's emphasis on the elderly's limitations establishes a contrast between the performers, which further accomplishes a social order where differences are highlighted.

The practice of inverting was materially mediated by turning to the photographic work of the Belgian-born artist Francis Alÿs who has developed images and videos of tornados that frequently occur at the end of the dry season in the dusty highlands south of Mexico City. In one video (shown both in Tate Modern and Museum of Modern Art), sequences of being absorbed by a sand cloud repeat themselves, which informed how Tornar became structured in contrasting rhythms of upheaval and (collective) rescue (see respectively Images 1 and 3). In one of the rehearsals, these visual materials were discussed among the dancers as conceptual inspiration to explore the metaphor of the tornado, understood 'as a tool to create a situation that allows us to question prejudices and stereotypes within a community' (subsidy application). As the group is scattered around, old positions and hierarchies have no longer any value. In this extreme situation, a kind of white canvas after the storm has died down, new relations with contrasting angles need to be explored if the group is to survive. As stated in UV's flyer on Tornar: 


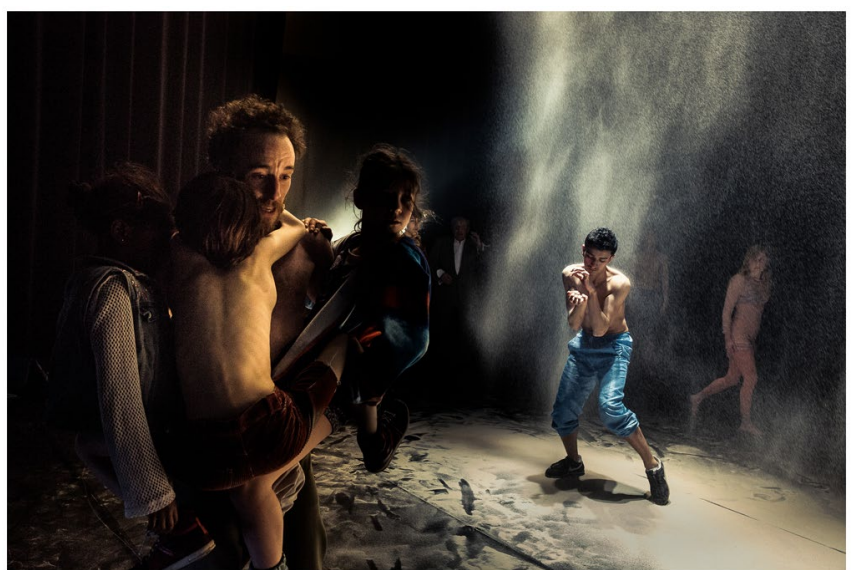

Image 3. A tornado scene in the dance performance Tornar Source: (C) Danny Willems

The tornado symbolizes destruction. It brings a tabula rasa where every prejudice has been erased. There is no longer a gap between younger and older generations. Here comes the moment where you can start again. Out of the blue.

Inverting roles and assumptions to highlight the contrast was also discursively accomplished through the choreographer's practical concern and artistic frame. Strongly orienting the activities of the group was the concern that everybody can learn from each other, whether one is a professional, a young child, an elderly women. This concern discursively mediated the practice of inverting, guiding the exercises and the exploration of new unfamiliar roles and movements as inspiration can come from everybody:

Whatever age you have, you know what a tornado is. Its force, speed and destructive beauty prompt everyone to move in a different way. Young and old, professional or non-professional, they will all without doubt influence each other during the rehearsal process. I am searching for a cross-pollination, a synergy. The elasticity and resilience of one person, the prudence and control of the other. The playfulness and freedom of one person in contrast to the sense of purpose and energy of another (subsidy application).

Also, the artistic frame of contrast and asymmetry discursively mediated this practice of highlighting difference. It impacted the decision of whom could be part of the cast of Tornar. Selecting individuals from the workshops for the dance production, the choreographer told in an interview the following:

'At the end, it was a hard choice between two children and two adolescents. I've asked myself then: Which adolescent gives "a counter color" to which child? Also, I first wanted to select two elderly persons, but ultimately, I thought it was way more 
interesting to work with only one old man. This way, I could better accentuate his loneliness' (interview).

Yet, while the search for contrast mediated the selection decision, it also caused disappointment of the elderly man who could not join the group for Tornar and who expressed this to us when we met him at another open dance workshop.

Reflecting on the effect of this practice, inverting thus involved reversing stereotypes and enlarging the differences through which the distinct characteristics of diverse individuals could be contrasted. It builds on the practice of mixing as the suspending of usual positions extends into exploring different, unusual and contrasting positions. Power asymmetries are not just bracketed but reversed. From this, multiplicity is further highlighted as new positions are made possible and existing positions are only valued, never downplayed. This practice thus implies a radical choice for new meaning, 'new understandings of how to do things', a crucial aspect of a practice (Schatzki, 2005). Yet, the danger of existing uneven positions to re-enter into the group was also present. We noticed how easy it sometimes was to fall back into the usual gender stereotypical relations as it were women who cared about the kids, or men who did the fast running in the exercises. Therefore, the practice of inverting requires a constant attention to the reversing of assumptions. Over time, we observed how in circle time and briefings this became not only a concern of the choreographer but of the whole group, constantly attending to how the differences are treated.

Inverting in other scenes of action. Turning to other scenes of action, we uncovered that the practice of inverting extended to reconfiguring the views and assumptions of other stakeholders in the broader field of dance. Important in this regard are the decision makers at the cultural houses, opting whether or not to schedule the intergenerational performance Tornar in their cultural season. While they themselves were rather open towards this experimental production - many of them provided support letters for the choreographer's subsidy application in which they agreed to schedule the production when it was finalized, they raised the issue of age classification. The administrative director of $\mathrm{UV}$, recalled in an interview how they got questions from theatre managers:

'For which age is it?'. Our answer that it was from 8 till 92 was bizarre to them. It did not fit into the classical system that segments performances into school, family and evening performance. In the end, Tornar was scheduled in each category.

The upsetting of this institutionalized way of approaching an audience also implied the creation of a diverse audience. Whereas school performances usually target particular age-ranges, Tornar (when scheduled as a school performance) was mostly played for an audience consisting of a mixture of younger and older children. 'Believe us: this is very rare, an exceptional occasion' according to a journalist.

In addition, the upsetting of views was oriented to the parents of children involved in the dance workshops. Sharing his experience in an international workshop on dance and children, organized by UV, the choreographer expressed how the 'parents are often the most difficult ones to manage' - a statement, as we could observe, full-hearted agreed on 
by all other choreographers and dancers. He further indicated how he changes language use: 'dance means girl, so I use a different word "theatre movement", I don't use the word dancing' - to convince some parents to allow their son to follow dance workshops.

Inquiring into the effect of these connections, we note how changing external stakeholders' current assumptions and their related power positions further enabled and highlighted the exploration of multiplicity. It educates external stakeholders into a new understanding of how to look at dance, thereby connecting the local accomplishment towards other activity bundles in the landscape of dance and slightly altering these latter. It is thus an important step in stabilizing the site of diversality, which is also further accomplished through the practice of affirming.

\section{The Practice of Affirming}

Affirming to strengthen embodiment. A final practice that accomplishes the inclusive social order is affirming or constantly experimenting with and repeating the new different, unusual and contrasting positions. This practice strengthens the newly established types of relations in an embodied way, developing implicit, collective skills and knowledge.

Observing the dance workshops and the repetitions of Tornar, we noted the continuous activities of warming up, training, improvising, exploring, noting down, videotaping, composing and aligning, reflecting, remembering and (self-) criticizing. As we can see in Image 1, these activities did not result in dance movements that mirror each other in perfectly symmetrical ways. Rather, in line with multiplicity, the dance evolved along spontaneous moves that contrast, yet also resonate with each other. The creation quest the artistic team undertook was one of producing and reproducing every time again movement exercises where every single dancer can add his or her own colour, and make a specific intonation to a move, yet always being responsive to what others initiate. Dancers were thus not pawns to execute a prescribed choreography but active inventors enacting a collective, reverberating improvisation.

The inclination to experiment was certainly materially mediated through the atmosphere of the physical rehearsal space. The studio of UV - an open, empty, all-black space (see Image 2) - feels, as participants often told us often during the breaks, as somehow '(an)other space'. Here, it was easier to try out new things and experiment with people you would usually not have imagined dancing with. And even more importantly, attention goes towards the qualities of the social space so that everyone can overcome their fear to experiment and to fail. Other important tools and arrangements were videos and try-outs to review the upcoming performance. Video-taping during the repetition offered visual feedback to all dancers of how their movements were in tune with each other and how their diverse bodies were well distributed in the space as they moved jointly. Public tryouts further confirmed the enactment of the multiplicity or suggested needed adaptations or further changes. As researchers, we often would be part of the audience and engaged in the debriefings afterwards. As these short public viewings came with a deadline, they often brought an increase of concentration, a different form of collective feedback but also an affective boost to the group's self-assurance through an early 'sense of success'.

The accomplishment of affirming was further discursively mediated through the choreographer's practical concern of concentration. Asking from his dancers movements 
that indicated genuine responses to others, concentration was key to perform this practice. We often observed how the choreographer was very strict, immediately calling the name of the dancer who did not give full attention or was too late in responding to an impulse of another dancer. Keeping concentration was a challenge as people became fatigued throughout the day, withdrawing themselves from the repetitive exercises.

Also the choreographer's artistic frame mediated the affirming. His vision on dance as a language that can connect without words is in line with the search for new embodied movements:

Tornar is a kind of 'ur-story', it resembles searching for the creation of the ever-first movement out of the absolute nothing, silence, devastation, perplexity. That is exactly why this is a dance performance. Movement communicates that what escapes words. It is an (un)conscious articulation of a shared trauma. Even if it pre-linguistic, it remains accessible to all (subsidy application).

Inquiring into the effect of this practice, we note how the long process of experimenting and repeating produced implicit, embodied knowledge. The series of exercises generated constantly smaller and larger differences, through which 'different bodies, habitual dispositions and subjectivities' emerge (Klein, 2017, p. 70, our translation). New contrasting movements were tried out until they were socially validated as collective embodied dispositions. The practice of affirming thus created learned abilities about how to go on, and how to carry out the specific doings and sayings of a practice (Nicolini, 2013; Schatzki, 2002), hereby confirming the possibility of new, equal relations. After two years of experimenting and trying out the force and possibility of multiplicity, the performance entitled 'Tornar' premiered.

Affirming in other scenes of action. Finally, the practice of affirming was strongly associated with experimentations in other dance workshops or public events of UV, which further enabled the development of collective connecting and bonding. For example, the group participated in several promotion events of dance that UV supported. At the 'Day of the Dance', a public workshop was organized giving the dancers a further possibility to engage and experiment with a very large and mixed audience. Or, at a local neighbourhood event, they performed on the central square their intergenerational dance, building confidence to perform for a public that is less acquainted with dance. The activity of affirming thus did not only occur in the rehearsal process of Tornar but was further associated and supported by related activities in other scenes of actions that similarly experiment with differences.

Overall, the practices of mixing, inverting and affirming form resources for each other through which the site of diversalizing gets more interconnected, supporting the further enactment of its constitutive practices. By connecting the performance of Tornar to new events and (often televised) public interactions, the dancers learned to work in an open way with diverse audiences so they could give their own direction to the dance performance. It brought along new moments of mixing with an even-more-diverse audience, which again was confronted with inverting their own expectations and usual positions. The stabilization of the site of diversalizing was further accomplished, even to 
the extent that the 'site of Tornar' became transformed into a next performance, entitled 'INVITED': a new, even more diverse site where the boundary between dancers and audience became radically questioned and where a new multiplicity emerged.

\section{DISGUSSION}

In this study, we examined an affirmative case of an inclusive social order to uncover situated and connected inclusion-producing practices. Taking a practice approach that subscribes to the idea that social life stems from and transpires through the real-time accomplishments of practices (Nicolini, 2013), we uncovered three interrelated practices: mixing, inverting, and affirming. Documenting these practices, we showed in-depth the activities underlying the accomplishment of inclusion, bringing 'empirical directness' (Vaara and Whittington, 2012) to a field that lacks insights on interventions that effectively foster inclusion (Dwertmann et al., 2016).

While these practices emerge from an affirmative and 'extreme' case, we believe with others who have studied dance performances (Harrison and Rouse, 2014) that the insights from this case can be developed into theoretical premises serving as inspiration for research in other contexts (Bansal, Smith and Vaara, 2018; Nicolini and Monteiro, 2017). First, we propose the novel notion of 'a site of diversalizing' to processually capture the accomplishment of multiplicity through practices and their associations in time and space. Second, we urge diversity scholars to no longer approach practice in a common sense way but as a theoretical notion, attending to the entanglement of the discursive, embodied and material components of human action. Third, we re-conceptualize context, arguing that inclusion and its conditions need to be theorized as strictly related and mutually implicated.

\section{Inclusion as a Site of Diversalizing}

The current focus on inclusion has instigated a new direction in the diversity literature. Rather than merely creating more diversity in organizations, scholars and practitioners are faced with the challenge to find ways to value diversity (Nishii and Rich, 2014). This requires not just a relabelling of long-established diversity management practices, but asks for radical change in which organizations are designed for the increasingly diverse people who populate organizations (Nkomo, 2014) and difference is no longer instrumentally appropriated in light of performance (Ahmed, 2012; Tyler, 2019). Our study contributes to understanding this radical change by revealing the intertwining of three practices in time and space that enabled (through mixing), highlighted (through inverting) and strengthened (through affirming) multiplicity, which we interpret as a 'site of diversalizing'.

The notion 'site of diversalizing' sheds a different light on inclusion-producing practices in two ways. First, we emphasize to understand the accomplishment of inclusion in a radical and processual way, calling this a process of diversalizing. Diversality or 'diversity as a universal project' is what Mignolo (2000), a critical scholar in literature and anthropology working on global coloniality, advocates as a view which 'celebrates difference and critiques all possible forms of fundamentalism' (p. 742). The only norm 
in a global society should be difference or the regulative principle of "yielding generously ("convivially" said Vitoria; "friendly" said Kant) toward diversity as a universal and cosmopolitan project in which everyone participates instead of "being participated"" (p. 744).

It is this view on diversity - difference as the core universal norm - that we see reflected in the range of practices that were repeatedly produced and reproduced in the dance company under study. New types of relations were established as multiplicity was the 'sine qua non' of social interaction (Ostendorp and Steyaert, 2009). Through the practice of mixing, people were 'forced' to interact with somebody from another age group, gender, ethnicity, hereby breaking the link with stereotypical norms and uneven positions and creating the possibility for people to develop open, affective bonds with unfamiliar others. Multiplicity was further enacted by the practice of inverting which highlighted the distinctiveness of differences and reversed uneven positions, making new meanings and understandings around diversity and dance possible. Finally, the practice of affirming additionally strengthened the multiplicity. Its activities of constantly repeating and experimenting with the new interactions led to the development of collective embodied dispositions, further stabilizing the processual accomplishment of inclusion.

Second, we emphasize that the inclusion-producing practices are no stand-alone practices but are intertwined in time and space. These spatio-temporal connections are crucial as, through making and breaking links (Shove, Pantzar and Watson, 2012), they reciprocally build and stabilize the 'site' of diversalizing. In particular, the practice of mixing broke the link with uneven, stereotypical positions that reflect power asymmetries and a new additional link was made with the activities of the dance organization to reach out to groups of individuals who usually do not have access to dance. These community activities became over time the resource for further mixing, setting in motion a reciprocal connection. The site was further built by the practice of inverting, not happening only within the group setting but also in other spaces, changing the assumptions of external stakeholders in the field of dance. The link between these practices started to stabilize the site of multiplicity as it reinforced the idea that intergenerational dance can be a legitimate, even innovative performance. Finally, over time, the practice of affirming with its experimentation in other public arenas further stabilized the site, reciprocally enabling and stabilizing the two other practices of mixing and inverting.

Taken together, we propose to understand an inclusive social order as a 'site' or a nexus of practices (Nicolini, 2011; Schatzki, 2005) where local accomplishments of addressing diversity and creating multiplicity are connected to other activities and practices both within the same time and space and across time and space, enabling each other in a reciprocal way. Our study thus takes a step forward by showing how the norm of the unencumbered (white) man can be challenged (Acker, 2006; Zanoni et al., 2010) or how to prevent that inclusion becomes appropriated as a managerial tool, managing difference in the name of performance (Ahmed, 2012; Tyler, 2019). Future studies might further advance this insight and similarly focus on the witnessing of real-time practicing that result in an inclusive social order. As actions are always enacted in a particular place and time, they might uncover other inspiring practices that equally break the link with inequality producing practices and/or that make new connections through which multiplicity is accomplished. 


\section{Practice as the Entanglement of Body, Materiality and Discourse}

Our study further contributes to diversity and inclusion research by clarifying what practices are. The notion of 'practice' features highly in writings on diversity, yet it tends to be taken for granted. By turning to practice theory and taking practice as the unit of analysis, we argue for a theoretical understanding of practice where a practice needs to be seen as the entanglement of body, materiality and discourse. Only this way can one understand the complexity of producing an inclusive organization. While we now discuss these three components separately, we emphasize their coming-into-connections (Gherardi, 2017) as also our analysis documented.

Our study clearly showed how the inclusion-producing practices involved the coming together of discursive, embodied and material components. Discursive practices were important as the expression of practical concerns (bringing on stage an image of society, learning from each other) and artistic frames (dance as genuine connections and asymmetrical movements) mediated the formation of new types of relations. Importantly, and in contrast to critical discursive diversity studies, these discursive practices are not privileged over other forms of social practices. From a practice lens, discourse and language, while being performative, cannot be assumed outside the ongoing social interactions. They thus 'lose their omnipotent status' (Reckwitz, 2002, p. 254) that they often receive in discursive studies. Or as stated by Nicolini (2013, p. 149), practice can only be understood and described 'as a publicly available accomplishment based on the situated assembling of a number of discursive and non-discursive practices'. Following this theoretical logic of a practice, diversity studies should avoid referring to talk only in order to understand practices or coming up with sensorially deprived and scarcely-recognizable accounts of practices (Nicolini, 2013). Rather, the focus would additionally be based on bodily movements and material tools.

Practice thus should also be appreciated as a bodily choreography. Our study clearly shows how the inclusive practices are accomplished through bodily interactions and affective resonances. While one could argue that relevance of embodiment is typical for a dance organization, practice theorists emphasize that 'practice often speaks through disciplined and habituated bodies' (Nicolini, 2013, p. 223). Many practices - think for instance of playing tennis, cooking but also teaching - can only be executed through the training of the body into a specific skilful performance. The practice lens thus urges diversity scholars to rethink studies that are based on the Cartesian dualism of mind and body - which is often the case in cognitive approaches - were the body executes in behaviour what the mind has prescribed (Reckwitz, 2002). Instead, following a postdualistic ontology, the body is not seen in contrast to the mind but the notion of practice intertwines body and mind, thought and action so that there is no longer priority given to the cognitive (nor the emotional). Human activity then happens because it is embodied - 'that is, interwined with the nature of the human body' (Bruni et al., 2005, p. 3). The body becomes the central locus or as stated by Reckwitz (2002, p. 251): 'if practices are the site of the social, then routinized bodily performances are the site of the social and so to speak - of "social order".

Other studies that attend to the embodied and affective nature of inclusion and diversity are increasingly developed in feminist organization theory and critical diversity 
studies (Fotaki and Pullen, 2019). Exemplary is the critical work on inclusion by Tyler (2019) who, by drawing on feminist writing on embodied ethics, emphasizes the importance of mutual recognition of our intercorporeal vulnerability to investigate how difference has the potential to rupture (rather than be made to fit into) the normative conditions of organizational life. She illustrates this theoretical critique with two examples of political activism - the anti-homophobic vigils held after the mass shootings at the Pulse nightclub in Orlando, June 2016, and the Women's Marches on the first full day of Donald Trump's US presidency - to highlight the meaning and potential of a sense of embodied interconnection or 'sheer sense of standing together, of embodying and recognizing opposition' (p. 58) as a way to rethink how inclusion might be understood and practiced.

To further develop the intersection between bodies, practices and inclusion, we believe, similar to Tyler's reliance on feminist work, that gender studies can help to articulate this direction. Conceiving gender as 'performatively constituted through cultural discourse and the materiality of the body' (Gond and Cabantous, 2016, p. 511), studies of gender performativity have taken corporeality seriously, showing how gendered relationships are accomplished through observing in detail how certain bodily schemata produce and reproduce routinized ways of gender-specific interactions (Poggio, 2006). Future research on inclusion could similarly pay attention to certain bodily motions, the display of specific emotions, and sensing the atmosphere of encounters between diverse employees (Fotaki and Pullen, 2019). This implies for instance a radical shift for studies on inclusive leadership as it shifts the attention away from individual leaders and their skills to the performance of everyday relations and to the question of how certain embodied practices and their affective nature can stabilize or disrupt the quality of relationships.

Next to discursive and bodily components, the role of materiality is essential to understand practice. Our study clearly shows how the inclusive practices under study are mediated through material artefacts (the dance studio, chairs) and social technologies (improvisation techniques, video-taping). When aiming to understand a practice, it is thus not enough to pay attention to discursive and bodily aspects but also to examine how, in combination, objects, tools and spaces are used in specific ways (Reckwitz, 2002). In particular, from a practice lens, intersubjective relations are no longer privileged above subject-object relations (Reckwitz, 2002), meaning that practices are as much intersubjective as inter-objective (Nicolini, 2013). The role of non-human actors has especially been emphasized in actor-network theory (Gherardi, 2016; Latour, 2005), granting equal agency to material things as necessary and active elements of human practice. While not all practice scholars follow the idea of equal agency, most of them acknowledge the active role of materiality in the performance of practices, highlighting that practices 'are inherently heterogeneous and sociomaterial' (Nicolini, 2013, p. 171). This position is well summarized by John Law (2009), who argues that in a heterogeneous world, if we want to understand something, we need to trace how human and nonhuman elements are assembled and how they 'together enact a set of practices that make a more or less precarious reality' (p. 151).

Aiming to understand inclusion-producing practices, diversity scholars are thus advised to attend to materiality as well and examine how certain artefacts (and their entanglement with body and discourse) contribute to the accomplishment of practices as well 
as the establishment of relationships between practices (Nicolini, 2013). To further develop such research, we again refer to performative studies of gender (Tyler and Cohen, 2010; Wasserman and Frenkel, 2015). For example, examining the relationship between organizational space, gender, and class, Wasserman and Frenkel (2015) highlighted how women from different occupational groups were actively engaged in different forms of discursive, material, embodied and emotional work through which they either reproduced or challenged the bureaucratic and masculine view of the space as constructed by architects and managers. This study is exemplary as it interweaves discursive, material, bodily and affective aspects of organizational practices of diversity and gender to understand organizations as inequality regimes.

Overall, by taking practice as a theoretical notion and attending to how discourse, body and materiality seamlessly blend in the accomplishment of a practice, diversity scholars would be better able to subscribe to the complexity of inclusion-producing practices. It is in this sense that Sandberg and Tsoukas (2016, p. 184) argue that practice theory is "part of a larger movement within the social sciences that emphasize "materiality", "embodiment", "emotions" and "practice", rather than the hitherto prevalent focus on cognition in various forms (e.g., cognitive schemata, interpretation, language, discourse) as a way to explain human action and social order'.

\section{Inclusion and its Conditions as a Site}

A final theoretical contribution refers to the re-conceptualization of context through the ontology of site. Currently, context in the inclusion and diversity literature tends to be approached in terms of structural, macro-level factors that 'can set specific constraints and opportunities' (Joshi and Roh, 2009, p. 601) on how diversity plays out in the workplace or that reflect 'a context of historically determined, structurally unequal access to and distribution of resources between socio-demographic groups' (Zanoni et al., 2010, p. 14). Further, to attend to context, there is a plea for a greater theoretical integration of various levels of analysis where especially meso and macro factors need to be incorporated into the study design instead of only being offered as post hoc explanation of unexpected findings.

Approaching diversity and inclusion from the ontology of practice theory and 'site' in particular sheds a different light on how to understand context. A site ontology depicts social life in relational terms as being composed by and transpiring through a bundle or network of practices. It holds that a social phenomenon is inherently tied to a kind of context which is 'as an arena or set of phenomena that surrounds or immerses something and enjoys powers of determination with respect to it' (Schatzki, 2005, p. 468). This view thus urges us to conceive the social phenomenon (inclusion in our case) and its conditions as strictly related and mutually implicated (Nicolini, 2011). It theorizes the recursive nature or mutually constitution between inclusion and its conditions, 'stipulating that no phenomenon can be taken to be independent of other phenomena' (Feldman and Orlikowski, 2011, p. 1242).

A site ontology thus moves away from the idea of 'levels' and its consequential call for multi- and cross-level studies. It questions 'the traditional idea that context is some kind of passive background' (Nicolini and Monteiro, 2017, p. 121). A site ontology is 
'flat' and context needs to be seen as part of how practices become accomplished. It is the relatedness of a variety of practices and the complexity that they often produce which is considered as 'contextualization'. As Schatzki (2005, p. 479) argues: 'No macro level of institutions and structures over and beyond interrelated bundles need be reified'. Inclusion-related concepts that are currently seen at meso or macro level such as inclusion climate thus need to be seen as consisting of concrete connections and interactions between the bundle of practice-arrangements (Schatzki, 2005). Rather than searching for different dimensions or features of an inclusion climate, a site ontology urges scholars to focus on interrelated practice-arrangement bundles, delving into the details of the connections and interactions between them (Nicolini, 2011).

Future research thus may advance our understanding of inclusion and its conditions by no longer focusing on one practice but zooming out and conducting a nexus analysis. Crucially, context is here not claimed a-priori but is empirically and analytically formed by tracing the connections and constellations between practices (Hui et al., 2017). Zooming out through a nexus analysis allows researchers to establish a practice's texture while holding on to its claim of a flat ontology (Schatzki, 2016). Thus, a nexus-analysis (Nicolini, 2013; Scollon and Scollon, 2004) gives inclusion and diversity researchers an alternative way to understand connections between what usually is a-priori distinguished as micro and macro through documenting how 'the macro' is achieved through maintaining the connections. Tracing and understanding context as the connections between practices is crucial both for inclusion-producing as inequality-producing practices. As our study shows, a nexus analysis makes visible how inclusion can emerge and become stabilized through intertwined practices but it can also show how inequality and discrimination are 'locked' into a nexus of practices and their associations that recursively produce enduring power asymmetries (Watson, 2017).

\section{The Specificity and Limitations of Our Study}

Our study is based on an affirmative case in the dance industry. While one might argue that the practices and its effects are very specific, we have shown its value for theory building in the above sections. Further, we believe that our insights are relevant and inspiring to other empirical settings. This is, as argued within inductive research, the case for settings with similar boundary conditions (Lincoln and Guba, 1985). For instance, our ideas can be applied to settings where new project groups are formed. Such settings are common in many organizations where the use of cross-disciplinary teams often drives complex problem solving and innovation. Here, practices of mixing, inverting and affirming may be initiated to create an inclusive social order. This would entail careful attention to membership, inviting employees who usually are not considered; reversing roles - for example, a relative newcomer would lead the team; and continuous attention to and affirmation of different ways of relating to each other so that a different understanding of how to do team work emerges and individuals embody this way of work. But moreover, we believe that rich descriptions of activities may help researchers and practitioners 'to see through conventional ways of doing and saying' and help them 'to explore the world of possibilities beyond what is currently the accepted norm' (Nicolini and Monteiro, 2017, p. 123). Our findings may thus serve as a tool for 
reflection, raising different questions and seeing new or unexpected connections that matter in context (Feldman and Worline, 2016).

Nevertheless, our study has its limitations. Our focus on a dance organization may have facilitated the possibility of multiplicity. The embodied nature of dance and the experimental nature of this dance production might in itself instigated an openness to others and embodied dispositions which we usually do not see in other types of organizations. Further, our insights on inclusion-producing practices are limited to 'building' multiplicity, instead of changing an existing, unequal organization. We thus have studied a case where inclusion could be produced in a rather 'free space' (Kellogg, 2009), away from inequality-producing practices. Isolation is indeed one of the important features of a relational space able to produce micro-institutional change (Kellogg, 2009).

Additional research is thus needed to search for an inclusive social order that was accomplished through practices that 'intervene' in exclusionary organizations. As suggested before, this is likely to involve not only new practices but as well interrogating the connections between practices which reinforce enduring power asymmetries (Watson, 2017) and breaking those linkages (Shove et al., 2012). Critical reflections on effective diversity management practices similarly move in this direction. For instance, the call for diversity practices that are part of larger organizational development initiatives (Benschop et al., 2015) or that redefine what is 'standard' in the employment relationship (Janssens and Zanoni, 2014) also highlights the need to broaden the scope and range of interventions. Studies that focus on how practices engage in the 'un-doing' of connections would thus increase our insight on the process through which inclusion can be accomplished in organizations with long-established inequality-producing practices.

Finally, our nexus analysis was limited to the way in which the three practices of mixing, inverting and affirming extended to other related scenes of actions. We did not further inquire into how these three inclusion-producing practices were connected to other types of practices such as decision making practices in the dance organization or the practice of subsidizing in the field of dance. Such inquiry would have provided a more complete image of the complexity that is produced in and around diversity and dance, offering further insight into the enabling and constraining processes of the wider site in which inclusion resides. Future research that enquires into such wider site of a practice might be especially needed when the social order is one of exclusion. It will help to further understand how the introduction of a practice is not to able to achieve its intended positive outcome because of the way practices are related to each other within a site as well as across different sites (Watson, 2017), that all reproduce and perpetuate inequality.

\section{GONGLUSION}

A long time ago, Deleuze and Guattari (1980, p. 5) said 'le multiple, il faut le faire'. By turning to the relational ontology of practice theory and an affirmative case, we focused on the witnessing of real-time practicing that accomplishes inclusion and we came across radically other kinds of practices and their connections that reciprocally enabled the production of multiplicity. Through this study, we hope to stimulate future research that similarly focuses on how an inclusive (as well as unequal) social order is always 'in 
the making' (Feldman and Orlikowski, 2011), uncovering the ongoing activities that produce (possibly transform) this social regularity. Such processual research has the potential to open a much richer understanding of how inclusion can be actually produced, attending to the arrangements of concrete elements instead of analytically hiding in vague notions or mechanisms (Nicolini and Monteiro, 2017).

\section{AGKNOWLEDGMENT}

The authors would like to thank all members of Ultima Vez and participants of dance workshops for their openness and hospitality. We are also grateful to Associate Editor Daniel Muzio and the three anonymous reviewers for their supportive and helpful comments throughout the revision process.

\section{REFERENGES}

Acker, J. R. (2006). 'Inequality regimes: Gender, class, and race in organizations'. Gender and Society, 20, 441-64.

Ahmed, S. (2012). On Being Included. London: Duke University Press.

Alvesson, M. and Sandberg, J. (2011). 'Generating research questions through problematization'. Academy of Management Review, 36, 247-71.

Bansal, P., Smith, W. K. and Vaara, E. (2018). 'From the editors - New ways of seeing through qualitative research'. Academy of Management fournal, 61, 1189-95.

Barnes, B. (2001). 'Practice as collective action'. In Schatzki, T. R., Cetina, K. K. and von Savigny, E. (Eds), The Practice Turn in Contemporary Theory. London: Routledge, 25-36.

Benschop, Y., Holgersson, C., van den Brink, M. and Wahl, A. (2015). 'Future challenges for diversity management in organizations'. In Bendl, R., Bleijenbergh, I., Henttonen, E. and Mills, A. (Eds), The Oxford Handbook of Diversity Studies in Organization and Management. Oxford: Oxford University Press, 553-74.

Boekhorst, J. A. (2015). 'The role of authentic leadership in fostering workplace inclusion: A social information processing perspective'. Human Resource Management, 54, 241-64.

Brimhall, K. G., Mor Barak, M. E., Hurlburt, M., McArdle, J. J., Palinkas, L. and Henwood, B. (2017). 'Increasing workplace inclusion: The promise of leader-member exchange'. Human Service Organizations: Management, Leadership \& Governance, 41, 222-39.

Bruni, A., Gherardi, S. and Poggio, B. (2005). Gender and Entrepreneurship. An Ethnographic Approach. London: Routledge.

Chia, R. and Holt, R. (2008). 'On managerial knowledge'. Management Learning, 39, 141-58.

Cox, T. H. and Blake, S. (1991). 'Managing cultural diversity: Implications for organizational competitiveness'. Academy of Management Perspectives, 5, 45-56.

Deleuze, G. and Guattari, F. (1980). Mille Plateaux. Paris: Editions de Minuit.

Dwertmann, D. J. and Böhm, S. A. (2016). 'Status matters: The asymmetric effects of supervisor-subordinate disability incongruence and climate for inclusion'. Academy of Management Fournal, 59, 44-64.

Dwertmann, D. J. G., Nishii, L. H. and van Knippenberg, D. (2016). 'Disentangling the fairness \& discrimination and synergy perspectives on diversity climate: Moving the field forward'. Fournal of Management, 42, 1136-68.

Ely, R. J. and Thomas, D. A. (2001). 'Cultural diversity at work: The effects of diversity perspectives on work group processes and outcomes'. Administrative Science Quarterly, 46, 229-73.

Feldman, M. S. and Orlikowski, W. J. (2011). 'Theorizing practice and practicing theory'. Organization Science, 22, 1240-53.

Feldman, M. S. and Worline, M. (2016). 'The practicality of practice theory'. Academy of Management Learning \&o Education, 15, 304-24.

Ferdman, B. M. (2014). 'The practice of inclusion in diverse organizations'. In Ferdman, B. M. and Deane, B. R. (Eds), Diversity at Work: The Practice of Inclusion. San Francisco, CA: Jossey-Bass, 3-54.

Ferdman, B. M. and Deane, B. R. (Eds) (2014). Diversity at Work: The Practice of Inclusion. San Francisco, CA: Jossey-Bass.

Ferdman, B. M. (2017). 'Paradoxes of inclusion: Understanding and managing the tensions of diversity and multiculturalism'. The Journal of Applied Behavioral Science, 53, 235-63. 
Finkel, R., Jones, D., Sang, K. and Russell, D. S. (2017). 'Diversifying the creative: Creative work, creative industries, creative identities'. Organization, 24, 281-88.

Fotaki, M. and Pullen, A. (Eds) (2019). Diversity, Affect and Embodiment in Organizing. Cham: Palgrave Macmillan.

Garfinkel, H. and Wieder, D. L. (1992). 'Two incommensurable, asymmetrically alternate technologies of social analysis'. Text in Context: Contributions to Ethnomethodology, 22, 175-206.

Gherardi, S. (2006). Organizational Knoweledge. The Texture of Workplace Learning. Oxford: Blackwell.

Gherardi, S. (2016). 'To start practice theorizing anew: The contribution of agencement and formativeness'. Organization, 23, 680-98.

Gherardi, S. (2017). 'Sociomateriality in posthuman practice theory'. In Hui, A., Schatzki, T. and Shove, E. (Eds), The Nexus of Practices. Connections, Constellations, Practitioners. New York: Routledge, 3-54.

Gond, J.-P. and Cabantous, L. (2016). 'Performativity. Towards a performative turn in organizational studies'. In Mir, R. A., Willmott, H. and Greenwood, M. (Eds), The Routledge Companion to Philosophy in Organization Studies. London: Routledge, 508-16.

Hardy, C. and Phillips, N. (2004). 'Discourse and power'. In Grant, D., Hardy, C., Oswick, C. and Putnam, L. (Eds), Handbook of Organizational Discourse. London: Sage, 219-318.

Harrison, S. H. and Rouse, E. D. (2014). 'Let's dance! Elastic coordination in creative group work: A qualitative study of modern dancers'. Academy of Management Fournal, 37, 1256-83.

Hui, A., Schatzki, T. and Shove, E. (2017). 'Introduction'. In Hui, A., Schatzki, T. and Shove, E. (Eds), The Nexus of Practices. Connections, Constellations, Practitioners. New York: Routledge, 1-7.

Janssens, M. and Steyaert, C. (2019). 'A practice-based theory of diversity: Re-specifying (in)equality in organizations'. Academy of Management Review, 44, 518-37.

Janssens, M. and Zanoni, P. (2014). 'Alternative diversity management: Organizational practices fostering ethnic equality at work'. Scandinavian Fournal of Management, 30, 317-31.

Joshi, A. and Roh, H. (2009). 'The role of context in work team diversity research: A meta-analytical review'. Academy of Management fournal, 52, 599-627.

Kalev, A., Dobbin, F. and Kelly, E. (2006). 'Best practices or best guesses? Assessing the efficacy of corporate affirmative action and diversity policies'. American Sociological Review, 71, 589-617.

Kellogg, K. C. (2009). 'Operating room: Relational spaces and microinstitutional change in surgery'. American Fournal of Sociology, 115, 657-711.

Klein, G. (2017). 'Tanz weitergeben. Tradierung und Übersetzung der Choreografien von Pina Bausch'. In Klein, G. and Göbel, H. K. (Eds), Performance und Praxis: Praxeologische Erkundungen in Tanz, Theater, Sport und Alltag. Bielefeld: Transcript, 63-87.

van Knippenberg, D. and Schippers, M. C. (2007). 'Work group diversity'. Annual Review of Psychology, 58, $515-41$.

Latour, B. (2005). Reassembling the Social: An Introduction to Actor-Network-Theory. Oxford: Oxford University Press.

Law, J. (2009). 'Actor network theory and material semiotics'. In Turner, B. S. (Ed.), The New Blackwell Companion to Social Theory. Oxford: Blackwell Publishing, 141-58.

Lincoln, Y. S. and Guba, E. G. (1985). Naturalistic Inquiry, 75, London: Sage Publications.

Lorbiecki, A. and Jack, G. (2000). 'Critical turns in the evolution of diversity management'. British fournal of Management, 11, 17-31.

Martin, P. Y. (2003). “Said and done" versus "saying and doing”". Gender \& Society, 17, 342-66.

Miettinen, R., Samra-Fredericks, D. and Yanow, D. (2009). 'Re-turn to practice. An introductory essay'. Organization Studies, 30, 1309-27.

Mignolo, W. (2000). 'The many faces of cosmo-polis: Border thinking and critical cosmopolitanism'. Public Culture, 12, 721-48.

Milliken, F. J. and Martins, L. L. (1996). 'Searching for common threads: Understanding the multiple effects of diversity in organizational groups'. Academy of Management Reviere, 21, 402-33.

Mor Barak, M. E. (2005). Managing Diversity: Toward a Globally Inclusive Workplace. Thousand Oaks, CA: Sage Publications.

Nicolini, D. (2009a). 'Zooming in and out: Studying practices by switching theoretical lenses and trailing connections'. Organization Studies, 30, 1391-418.

Nicolini, D. (2009b). 'Articulating practice through the interview to the double'. Management Learning, 40, 195-212.

Nicolini, D. (2011). 'Practice as the site of knowing: Insights from the field of telemedicine'. Organization Science, 22, 602-20.

Nicolini, D. (2013). Practice Theory, Work and Organization. Oxford: Oxford University Press. 
Nicolini, D. (2017a). 'Practice theory as a package of theory, method and vocabulary: Affordances and limitations'. In Jones, M., Littig, B. and Wroblenski, A. (Eds), Methodological Reflections on Practice Oriented Theories. Berlin: Springer, 19-34.

Nicolini, D. (2017b). 'Is small the only beautiful? Making sense of 'large phenomena' from a practice-based perspective'. In Hui, A., Schatzki, T. and Shove, E. (Eds), The Nexus of Practices. Connections, Constellations, Practitioners. New York: Routledge, 98-113.

Nicolini, D. and Monteiro, P. (2017). 'The practice approach: For a praxeology of organizational and management studies'. In Langley, A. and Tsoukas, H. (Eds), The Sage Handbook of Process Organization Studies. London: Sage, 110-26.

Nishii, L. H. (2013). 'The benefits of climate for inclusion for gender-diverse groups'. Academy of Management Fournal, 56, 1754-74.

Nishii, L. H. and Mayer, D. M. (2009). 'Do inclusive leaders help to reduce turnover in diverse groups? The moderating role of leader-member exchange in the diversity to turnover relationship'. Fournal of Applied Psychology, 94, 1412-26.

Nishii, L. H. and Rich, R. E. (2014). 'Creating inclusive climates in diverse organizations'. In Ferdman, B. M. and Deane, B. R. (Eds), Diversity at Work: The Practice of Inclusion. San Francisco, CA: Jossey-Bass, 330-63.

Nkomo, S. M. (2014). 'Inclusion: Old wine in new bottles?'. In Ferdman, B. M. and Deane, B. R. (Eds), Diversity at Work: The Practice of Inclusion. San Francisco, CA: Jossey-Bass, 580-92.

Nkomo, S. M., Bell M. P., Joshi, A., Roberts, L. M. and Thatcher, S. (2019). 'Diversity at a critical juncture: New theories for a complex phenomenon'. Academy of Management Review, 44, 498-517.

Noon, M. (2007). 'The fatal flaws of diversity and the business case for ethnic minorities'. Work, Employment and Society, 21, 773-84.

Orlikowski, W. J. (2000). 'Using technology and constituting structures: A practice lens for studying technology in organizations'. Organization Science, 11, 404-28.

Ostendorp, A. and Steyaert, C. (2009). 'How different can differences be (come)?: Interpretative repertoires of diversity concepts in Swiss-based organizations'. Scandinavian Fournal of Management, 25, $374-84$

Poggio, B. (2006). 'Editorial: Outline of a theory of gender practices'. Gender, Work \& Organization, 13, 225-33.

Randel, A. E., Galvin, B. M., Shore, L. M., Ehrhart, K. H., Chung, B. G., Dean, M. A. and Kedharnath, U. (2018). 'Inclusive leadership: Realizing positive outcomes through belongingness and being valued for uniqueness'. Human Resource Management Review, 28, 190-203.

Reckwitz, A. (2002). 'Towards a theory of social practices: A development in culturalist theorizing'. European Fournal of Social Theory, 5, 243-63.

Roberson, Q. M. (2006). 'Disentangling the meanings of diversity and inclusion in organizations'. Group \&o Organization Management, 31, 212-36.

Roberson, Q. M. (2013). The Oxford Handbook of Diversity and Work. Oxford: Oxford University Press.

Sandberg, J. and Dall'Alba, G. (2009). 'Returning to practice anew: A life-world perspective'. Organization Studies, 30, 1349-68.

Sandberg, J. and Tsoukas, H. (2011). 'Grasping the logic of practice: Theorizing through practical rationality'. Academy of Management Review, 36, 338-60.

Sandberg, J. and Tsoukas, H. (2016). 'Practice theory: What it is, its philosophical base, and what it offers organization studies'. In Mir, R. A., Willmott, H. and Greenwood, M. (Eds), Companion to Philosophy in Organization Studies. New York: Routledge, 184-98.

Schatzki, T. R. (2001). 'Introduction: Practice theory'. In Schatzki, T. R., Cetina, K. K. and von Savigny, E. (Eds), The Practice Turn in Contemporary Theory. London: Routledge, 1-14.

Schatzki, T. R. (2002). The Site of the Social: A Philosophical Account of the Constitution of Social Life and Change. University Park, PA: The Pennsylvania State University Press.

Schatzki, T. R. (2005). 'The sites of organizations'. Organization Studies, 26, 465-84.

Schatzki, T. R. (2016). 'Practice theory as flat ontology'. In Spaargaren, G., Weenink, D. and Lamers, M. (Eds), Practice Theory and Research: Exploring the Dynamics of Social Life. Abingdon: Routledge, 18-42.

Scollon, R. and Scollon, S. W. (2004). Nexus Analysis: Discourse and the Emerging Internet. New York: Routledge.

Shore, L. M., Randel, A. E., Chung, B. G., Dean, M. A., Erhrhart, K. H. and Singh, G. (2011). 'Inclusion and diversity in work groups: A review and model for future research'. Fournal of Management, 37, 1262-89.

Shore, L. M., Cleveland, J. N. and Sanchez, D. (2018). 'Inclusive workplaces: A review and model'. Human Resource Management Review, 28, 176-89. 
Shove, E., Pantzar, M. and Watson, M. (2012). The Dynamics of Social Practice: Everyday Life and How It Changes. London: Sage.

Steyaert, C. (2016). "After" context'. In Welter, F. and Gartner, W. B. (Eds), A Research Agenda for Entrepreneurship and Context. Cheltenham: Edward Elgar Publishing, 28-40.

Tyler, M. (2019). 'Reassembling difference? Rethinking inclusion through/as embodied ethics'. Human Relations, 72, 48-68.

Tyler, M. and Cohen, L. (2010). 'Spaces that matter: Gender performativity and organizational space'. Organization Studies, 31, 175-98.

Vaara, E. and Whittington, R. (2012). 'Strategy-as-practice: Taking social practices seriously'. The Academy of Management Annals, 6, 285-336.

Wasserman, V. and Frenkel, M. (2015). 'Spatial work in between glass ceilings and glass walls: Genderclass intersectionality and organizational aesthetics'. Organization Studies, 36, 1485-505.

Watson, M. (2017). 'Placing power in practice theory'. In Hui, A., Schatzki, T. and Shove, E. (Eds), The Nexus of Practices. Connections, Constellations, Practitioners. New York: Routledge, 169-82.

Yanow, D. and Schwartz-Shea, P. (2006). Interpretation and Method. Empirical Research Methods and the Interpretive Turn. New York/London: ME Sharpe.

Ybema, S., Yanow, D., Wels, H. and Kamsteeg, F. H. (2009). Organizational Ethnography: Studying the Complexity of Everyday Life. London: Sage.

Zanoni, P. and Janssens, M. (2004). 'Deconstructing difference: The rhetoric of human resource managers' diversity discourses'. Organization Studies, 25, 55-74.

Zanoni, P. and Janssens, M. (2015). 'The power of diversity discourses at work: On the interlocking nature of diversities and occupations'. Organization Studies, 36, 1463-83.

Zanoni, P., Janssens, M., Benschop, Y. and Nkomo, S. (2010). 'Unpacking diversity, grasping inequality: Rethinking difference through critical perspectives'. Organization, 17, 1-21. 